\title{
REFLEXIONES SOBRE EL ESPACIO GEOGRÁFICO Y SU ENSEÑANZA
}

\author{
POR \\ FERNANDO ARROYO ILERA \\ $\mathrm{Y}$ \\ AMPARO PÉREZ BOLDO
}

\begin{abstract}
¿Cuál es el fin último de la enseñanza de la Geografía?, ¿qué debe entenderse por conocimiento procedimental en Geografía?, ¿cómo se enseña Geografía? Estas y otras muchas preguntas por el estilo se repiten constantemente siempre que abordamos el espinoso tema de la didáctica de esta disciplina, corolario inevitable de la casi eterna discusión epistemológica sobre su concepto y metodología. Tras unos años en los que los estudios geográficos descansaron en la más completa asepsia teórica, vinieron otros en los que el único objeto de la Geografía parecía ser la constante y reiterada introspeccción sobre la razón de ser de sus contenidos científicos, de su orientación epistemológica y de su transcendencia metodológica. Se sucedieron así tendencias y posturas que se definían, ante todo, por la crítica que hacían de sus predecesoras, más que por la evidencia de sus aportaciones. Tendencias que, en gran medida, sólo buscaban reflejar en el campo geográfico las orientaciones que se producían y caracterizaban a otras ciencias próximas. Así, a la Geografía llamada clási-
\end{abstract}

Fernando Arroyo Ilera. Departamento de Geografía-ICE

Amparo Pérez Boldo. ICE. Universidad Autónoma. Madrid

Estudios Geográficos

Tomo LVIII, n. ${ }^{\circ} 229$, octubre-diciembre 1997 
ca, de contenido regional y descriptivo, sucedió la «nueva» Geografía analítica o teórica de configuración matemática, que pronto recibió las críticas de los agresivos geógrafos radicales de influencia marxista, para terminar todos ellos diluyéndose en un amplio eclecticismo con perceptivistas, behavioristas y humanistas entre otros. Todo ello es tema ya suficientemente conocido, ejemplo como pocos de discusión academicista que si a sus protagonistas producía insatisfacción y desasosiego, a los profesores de Geografía y a otros usuarios de la misma les creó desconcierto y perplejidad (Capel, 1981).

Porque lo único claro de la polémica era que la Geografía siempre ha tenido, al margen de las discusiones aludidas, un evidente contenido educativo, sobre todo en nuestra época, cuando problemas de indudable trascendencia geográfica y espacial: contaminación, crecimiento demográfico, agotamiento de recursos, desaparición de naciones, nacimiento de otras nuevas, redifiniciones fronterizas, etc. constituyen temas de permanente actualidad. Hoy día, más que nunca, se puede dudar que la Geografía sea una ciencia, pero no que sus contenidos, con independencia de como hayan sido elaborados, tengan una esencial aplicación educativa. Es decir, al margen de cualquier política científica o didáctica, y con independencia del nombre que se le dé o del rango jerárquico que se le confiera, ningún currículo escolar o programación educativa, ningún sistema de enseñanza pueden ser tales si prescinden de promover el aprendizaje de las relaciones del hombre con su medio y de sus mutuas influencias, que es lo que siempre ha estudiado la Geografía.

Claro está que entonces surgen otros problemas a los que la Geografía ha prestado, por lo general, escasa atención. Para que una ciencia cualquiera se pueda enseñar, es decir, sea también una disciplina docente, hace falta que a la lógica de sus contenidos científicos se añadan los criterios de organización y transmisión que se adecúen a los procesos de aprendizaje de los alumnos. Estos mecanismos suponen una organización didáctica de dichos contenidos $\mathrm{y}$, sobre todo, una ordenación de los mismos considerando como aprenden los alumnos a los que van dirigidos. Sin ello no puede decirse en propiedad que la geografía sea una auténtica disciplina educativa, por muy formativo que pueda resultar la adquisición de sus contenidos conceptuales y de las destrezas procedimentales que le son propias. Esta carencia, que normalmente ha sido suplida con creces por la expe-

$$
-514-
$$


riencia y la intuición del profesor, requiere cada vez más el concurso de teorías y prácticas de instrucción.

Así continuamos con las preguntas iniciales: ¿cómo aprende un alumno cualquiera de Geografía?, ¿cuáles son sus ideas previas sobre lo que va a aprender?, ¿cómo deben oganizarse los contenidos geográficos que recibe?, ¿qué estrategias emplear para ello?, etc. Este es el tema que aquí pretendemos abordar como una reflexión previa para una didáctica específica de la Geografía en cuanto disciplina educativa, para lo cual adelantamos que partimos de tres presupuestos básicos: las características del alumno y las peculiaridades de su aprendizaje, la estrucura epistemológica y jerarquía conceptual de los contenidos geográficos que se pretenden enseñar, especialmente el concepto y caracteres del espacio geográfico, y las habilidades y capacidades que se consideran propios del saber procedimental en geografía y se busca que el alumno adquiera en su proceso de enseñanza.

\section{El desarrollo cognitivo y la experiencia previa del alumno}

Las condiciones y circunstancias del alumno que recibe la información y es sujeto del aprendizaje es el primer punto ineludible de toda reflexión educativa. Aceptando el principio genérico constructivista de que todo conocimiento se construye sobre lo que ya se sabe, para diseñar una estrategia de enseñanza de la Geografía hace falta conocer una serie de aspectos esenciales que intervienen en el proceso. En primer lugar, y desde una perspectiva evolutiva, es preciso tener en cuenta la edad de alumno, aspecto largamente tratado en la práctica educativa, sobre todo, bajo la influencia de las teorías de Piaget sobre los procesos de desarrollo cognitivo y configuración del pensamiento formal. Consecuencia de ello fue su concepción de la evolución de las nociones espaciales en el niño como parte del proceso más amplio de paso del pensamiento concreto al formal. En síntesis, este proceso evolutivo, en lo relativo a la configuración de las ideas espaciales, se desarrolla en tres secuencias.

1. ${ }^{a} \quad$ En la primera, los sistemas de referencia espaciales son básicamente egocéntricos, pues el entorno se descubre desde y en relación con el propio sujeto, con quien cada objeto establece una mera relación topológica de proximidad o lejanía. 
2. ${ }^{\mathrm{a}} \quad$ Paulatinamente se van estableciendo sistemas de referencia coordinados entre sí, lo que permite apreciar la existencia de grupos fijos, internamente proyectivos.

$3 .^{a} \quad$ Por último, la última fase conduce a la configuración de sistemas de referencia coordinados de forma abstracta, con total independencia del sujeto, lo que posibilita nociones espaciales de carácter euclideano (Ochaita y Huertas, 989).

Este desarrollo de las nociones espaciales, de fundamentación claramente evolutiva, evidencia en realidad distintos estadios cognitivos con virtualidades, no sólo en las etapas de desarrollo intelectual, sino en otras muchas situaciones, y aunque Piaget estaba pensando más en el espacio de la Geometría que el de la Geografía, sus consecuencias sobre la enseñanza de esta última han llegado hasta nosotros. Así, Graves (1980) establece la primacía, en los primeros estadios de la percepción geográfica, de lo particular y concreto sobre lo más general y abstracto (por ejempo, la colina sobre el paisaje), lo que conlleva ciertas dificultades, según la edad, para comprender la perspectiva tridimensinal. De la misma manera, a ello se debe una mayor facilidad para la comprensión del lenguaje cartográfico sobre el verbal, siempre que aquél se refiera a espacios previamente conocidos, pues si no se trataría de un proceso deductivo. En el mismo sentido, Debesse-Arviset (1968) ha resaltado las dificultades que, según su edad, los alumnos pueden tener para la correcta comprensión del espacio curvo y de todas sus consecuencias geográficas, como movimientos de la Tierra, sucesión de días y noches, estaciones, equinocios, etc. En este mismo sentido, Pedro Plans (1967) sostuvo, en su momento, la necesidad de confrontar los niveles de estudio de la Geografía con la edad de los alumnos. Así, entre los cinco y los siete años el niño está dominado por su ambiente y no es capaz de imaginar unas condiciones diferentes de las que le rodean. Entre los ocho y los nueve años recomienda actividades de tipo práctico y el fomento de capacidades como la observación. Sólo a partir de los diez años comienza el desarrollo de lo que, citando a Debesse, llama pensamiento nocional, y que posibilita el estudio sistemático de la Geografía.

Por último, Bale se aparta sustancialmente del esquema evolutivo y, más en línea con otras concepciones del aprendizaje (expertos-novatos) pone de manifiesto que en la configuración de dichas percep- 
ciones geográficas intervienen no sólo la edad, sino también la experiencia espacial. Así, dicho autor destaca la influencia del habitat, con diferentes experiencias en los alumnos del campo que en los de la ciudad, sexo, según las diferentes «áreas de permiso» de los niños respecto a las niñas, o raza, en los casos en que ese factor determine «áreas de rechazo» y distintas experiencias espaciales.

Estas últimas experiencias nos llevan a plantear el segundo tema capital para definir la posición del alumno: el de las ideas previas, o conocimientos que éste ya tiene. En lo relativo a la Geografía este conocimento es de tres tipos: esquemas apriorísticos, ideas adquiridas de forma espontánea o intuitiva, que por regla general son de carácter antropocéntrico y antropométrico, reflejo de relaciones y experiencias cotidianas y con una gran carga afectiva y, por último, las concepciones culturales propias de una determinada época o sociedad, que en nuestro caso son, por lo general, de configuración geométrica y abstracta. Así, en una obra clásica de un psicólogo sobre el tema (Lynch, 1960), se distingue entre las diferentes imágenes mentales del propio entorno urbano, que los individuos desarrollan según su propia experiencia cotidiana. Entre dichas imágenes, o ideas previas, Lynch diferencia mojones o hitos, rutas y configuraciones, según distinto grado de abstracción y en relación, en gran medida, con la propia actividad que realizan los individuos. Los mojones son elementos singulares y significativos de una determinada situación urbana y personal, que generan imágenes concretas y, por lo general, bien definidas que actúan como referentes urbanos de primera categoría. Las rutas, por el contrario, responden a una experiencia directa. Se corresponderían a sistemas de referencia coordinado entre sí, que el sujeto conoce bien debido al grado de utilización que hace de la misma. Por último las configuraciones, en cuanto imágenes más complejas de realidades urbanas más amplias, descansan en una noción global del espacio y requieren una experiencia urbana más completa y abstracta. Lynch observó, por último, que la imagen urbana variaba de unos individuos a otros según la práctica urbana y, en cierto modo, la cultura espacial de cada uno, lo que, a nuestros efectos, es una buena prueba de conocimientos previos esenciales en el proceso de aprendizaje de toda persona.

La misma fundamentación es la que explica la configuración de los mapas mentales, o representación intelectual que cada individuo 
tiene de su ambiente espacial, lo que condiciona su actitud y comportamiento ante el mismo. Dicha representación está condicionada, a su vez, por la propia percepción, experiencia, cultura, etc. y constituye, por su misma naturaleza, un instrumento fundamental para conocer la configuración que cada individuo tiene de su entorno y poder dirigir así su propio aprendizaje espacial. De esta forma, junto a las ideas espaciales de carácter innato, cobran importancia los aspectos experienciales, que permiten distinguir diferencias de nociones y capacidades tanto de carácter personal como social (Herrero, 1992).

Pero estas nociones espaciales, imágenes mentales y mapas cognitivos del entorno no son más que representaciones individuales sobre las que se imponen los elementos culturales de carácter colectivo. Estos actúan desde el primer momento y se corresponden con el grado de complejidad intelectual de cada cultura. Nuestra época puede así caracterizarse por un elevado nivel de abstracción en los procesos de comprensión espacial, al igual que en otras manifestaciones culturales, estéticas, científicas, etc. Por ello, nuestras nociones y capacidades espaciales tienen un marcado carácter geométrico o matemático, que la propia inercia cultural nos lleva a considerar como innatos y espontáneos, cuando muy al contrario son productos muy elaborados de la evolución cultural. Hace ya algún tiempo que un prestigioso sociólogo, Lewis Mumford (1934:35) puso de manifiesto como cada época vive bajo una forma distinta de espacio y de tiempo. En la nuestra, ambos conceptos son una clara consecuencia del matematicismo y del racionalismo ilustrado y de las exigencias de la revolución industrial. Anteriormente se daban visiones más intuitivas y menos precisas, de carácter antropogénico y configuración analógica respecto a hechos y fenómenos humanos; visiones que, por lo general, han perdido operatividad respecto al código cultural de nuestra época, pero no significatividad respecto a los procesos de aprendizaje de conceptos $\mathrm{y}$, sobre todo, de determinados procedimientos espaciales.

Por último, más recientemente, un geógrafo «humanístico» Yi Fu Tuan (1974), ha centrado su teoría en las relaciones afectivas que se establecen entre el medio y el sujeto, con independencia de la edad y en clara relación con la experiencia de éste respecto a aquél. Estas relaciones son consecuencia también de todo un orden complejo de sensaciones, sentimientos, valores, etc. lo que le ha llevado a elabo- 
rar los conceptos de topofilia, topofobia y otros parejos como la topolatría, etc. sentimientos espaciales de atracción, repulsión y veneración respectivamente que experimenta toda persona y que son fundamentales para comprender su comportamiento espacial y necesario tener en cuenta, en todo proceso de enseñanza-aprendizaje de esta disciplina. Se trataría, pues, de un orden de «sentimientos previos» en el terreno afectivo, de similar funcionalidad a los conocimientos previos en lo cognitivo.

El contenido de la educación geográfica.

El problema de los conceptos básicos

Conocimientos y conceptos básicos constituyen un problema esencial de toda disciplina educativa, en cuanto suponen una reflexión sobre la ciencia correspondiente y, a la vez, sobre la «significatividad» de la misma, en el sentido ausubeliano del término. Por lo que respecta a la Geografía, el tema se complica por el tradicional carácter descriptivo de accidentes y de hechos únicos e individuales que ha caracterizado el saber geográfico, y sobre todo su enseñanza, durante mucho tiempo. En efecto, el descriptivismo geográfico ha sido considerado tradicionalmente como ejemplo representativo del aprendizaje memorístico e inoperante, que terminó provocando la crisis del propio discurso científico de la Geografía descriptiva y regional y la búsqueda de otros planteamientos más generalizadores y analíticos. A este respecto, hay que tener presente que los datos y hechos individualizados, los «accidentes» geográficos, constituyen en sí mismos materia de conocimiento geográfico no formalizado $\mathrm{y}$, en consecuencia, de escasa incidencia científica e interés educativo muy marginal, pero ello no quiere decir que no tengan su importancia desde ambos puntos de vista, pues pueden llegar a constituir elementos esenciales en el proceso de conceptualización si son tratados debidamente.

Lo fundamental es precisar que tipos de conceptos y relaciones caracterizan a la Geografía y que nivel de significatividad puede esperarse de su aprendizaje. En este sentido la primera dificultad, tanto del discurso científico como de su enseñanza, es la diferencia entre conceptos físicos, propios del medio natural, precisos y bien 
delimitados, de los propios del medio social, mucho más difusos e identificables, en el mejor de los casos, con prototipos representativos $\mathrm{y}$, lo que es más importante, la necesidad de establecer y estudiar las relaciones entre ambas formas de conceptualización tan diferentes. En ello radica, desde el punto de vista cognitivo, la dificultad para lograr la «síntesis» tan querida a la Geografía Clásica y de tan difícil logro en la práctica.

Este problema enlaza con el tema de la delimitación de los saberes básicos que definen a toda ciencia lo que es imprescindible para promover su aprendizaje significativo. Es decir, ¿qué es lo que realmente estudia la Geografía y lo qué pretendemos que aprenda un alumno de esta disciplina? La pregunta puede contestarse desde diversas perspectivas y según la concepción que cada uno tenga de lo que es la Geografía y la educación, pero a modo de ejemplo podemos citar tres opiniones altamente cualificadas y representativas. Así, para Walker (1975), los conceptos básicos en la enseñanza de la Geografía serían los de localización, interacción, escala, distancia y cambio. Más preciso, Pinchemel (1982) diferencia tres niveles de conceptualización de los hechos y fenómenos geográficos. El primero se refiere a todo lo relativo a la localización, con estudio de los procesos de distribución y diferenciación espacial, es decir, las relaciones entre hechos, lugares y espacio. El segundo es el realtivo al análisis ambiental, que estudia las relaciones entre el espacio físico y el humano y entre los diferentes tipos de conceptos antes aludidos. Por último, la organización espacial, con los problemas relativos a la configuración regional. Por último, Catling (1976), muy sintético resumen los conceptos básicos del estudio geográfico en tres nociones fundamentales: situación espacial, distribución espacial y relaciones espaciales. En nuestro país, por último, Horacio Capel y Luis Urteaga (1987), elaboraron una lista de dieciocho conceptos y postulados básicos que pretenden recoger, y se resumen, en los tres enfoques clásicos del pensamiento geográfico: estudio de distribuciones, análisis de la localización y reflexiones de las relaciones del hombre con su medio ambiente. Y en este mismo sentido las referencias pueden ser interminables.

Pero la mayoría de ellas presentan un denominador común y un equívoco común. Aquél es el substrato espacial que existe en todas esas definiciones de conceptos básicos en Geografía, como no podía ser de otra manera, aunque muchas de ellas se refieren a conceptos 
espaciales y no al espacio geográfico propiamente dicho. Nosotros pensamos, por el contrario, que dicha reflexión debe girar en torno a los problemas didácticos que plantea la enseñanza del espacio geográfico en su totalidad. Este, y no sus conceptos subordinados, debe ser el auténtico concepto básico de nuestra disciplina. Efectivamente, la Geografía es en nuestros días, y cada vez más, una ciencia espacial, bajo el epígrafe que a este concepto quiera dársele: lugares, territorio, paisaje o espacio propiamente dicho. Ciencia de las relaciones Hombre-Medio, de las influencias del segundo sobre el primero y de las acciones de aquél sobre éste, el espacio geográfico es, no obstante, un término necesitado de definición y, aun más, de conceptualización, tanto a efectos epistemológicos de la propia ciencia, como sobre todo a efectos didácticos para su enseñanza.

Respecto a la segunda característica común de todas aquellas aportaciones, es la confusión que la mayoría de ellas presentan entre conceptos y procedimientos, es decir, entre nociones espaciales propiamente dichas y las capacidades y destrezas inherentes a su posesión. Esas capacidades espaciales a la que se refieren los tres autores citados, esos saberes geográficos no bien definidos es lo que, hoy día, llamamos conocimiento procedimental. Como es sabido en este tipo de conocimiento, es decir, aquel que consiste en saber hacer y que a diferencia del conocimiento declarativo no se expresa verbalmente, sino que se manifiesta en la acción, radica el auténtico conocimiento humano (Anderson, 1983, Aparicio, 1995). Vulgarmente se simplifica esa definición identificando el conocimiento procedimental con la simple práctica instrumental, lo que puede ser correcto respecto a ciertas técnicas elementales. Pero no ocurre así cuando nos referimos a saberes complejos, muy elaborados, como la Geografía, que, además de la mera destreza instrumental, requieren la incorporación de amplios conocimientos teóricos.

Trataremos, pues de analizar estos dos aspectos básicos en la enseñanza de la Geografía, para precisar después como contribuir a una educación especial cada vez más necesaria en nuestra época.

\section{La noción y el concepto de espacio geográfico}

Pero también aquí hay unas cuestiones previas. El tema del conocimiento del espacio no es sólo, ni siquiera primordialmente, una 
cuestión geográfica. Se encuentra en el mismo centro de cualquier problema de teoría del conocimiento. ¿Es una realidad o una noción? De forma común y espontánea se viene a considerar que el espacio tiene una realidad en sí mismo, con independencia de su contenido o de la aprensión cognitiva que el sujeto realice sobre él. Por otro lado, desde una perspectiva más intelectual, se considera todo lo contrario: el espacio es una construcción de la mente, una noción que permite la cognición, o si se quiere en términos kantianos una "forma a priori de sensibilidad", idea previa por antonomasia que posibilita $\mathrm{y}$ sobre la que se estructura el mismo conocimiento.

Por ello, cuando afirmamos que la Geografía es una ciencia espacial, conviene también que precisemos la perspectiva espacial que dicha afirmación lleva implícita $\mathrm{y}$, de la misma forma, tengamos en cuenta cuál es la idea previa que tienen nuestros alumnos, si lo que queremos es enseñar una determinada visión de ese mismo espacio geográfico. En nuestro caso, esas perspectivas tienen frecuentemente reflejo terminológico. El mismo Bunge (1962) llamó, en su día, la atención sobre como en la polémica póstuma entre Hartshorne y Schaefer sobre el «excepcionalismo» de la Geografía, el primero utiliza siempre el nombre de «lugar» para referirse a lo que el segundo llama normalmente «espacio». Pero dicha polémica no fue sólo por diferencias terminológicas, sino que bajo esa apariencia se escondía, como es sabido, una auténtica pugna teórica.

A rasgos generales, es posible diferenciar tres nociones diferentes sobre nuestro entorno, que tanto los geógrafos como el hombre de la calle, utilizan cuando se refieren al espacio geográfico. Estas nociones responden, por lo general, a distintas tendencias epistemológicas y cognitivas, pero se manejan frecuentemente de forma indistinta, incluso se superponen en ocasiones. Por un lado, es preciso distinguir entre el espacio material, concreto y directo, en el que tiene lugar todo tipo de actividades humanas, en cierta manera, asimilable a territorio y a los lugares vidalianos, y el espacio abstracto, de configuración geométrica que resulta de la aplicación al anterior de los esquemas espaciales de la cultura de nuestra época. A este respecto, Paul Zumthor (1993:51) llamó la atención, en su día, sobre la ausencia, en los idiomas medievales, de cualquier término que permitiera explicar, siquiera de forma aproximada, nuestra actual idea de espacio abstracto. En su lugar, todos los términos utilizados derivados de 
muy distintas raíces, como los latinos locus y platea, el germánico rum, y el anglo stede, indican un emplazamiento concreto y determinado. Por el contrario las palabras derivadas del vocablo latino spatium son términos cultos, que no aparecen en el lenguaje común hasta época muy tardía y siempre con un sentido de intervalo cronológico o topográfico, es decir, como sinónimo de vacio.

Por otro lado, ese espacio abstracto puede ser concebido como un ente absoluto, con existencia real en sí mismo con independencia de los elementos que lo integran. Es decir, comprende tanto el continente como todo tipo de contenido. Se trata de un espacio tridimensional e isotrópico. Esta noción absoluta se corresponde, con relativa exactitud, con el concepto de espacio único e irrepetible propio de la Geografía clásica. Pero, junto a ello, son cada vez más frecuentes la aplicación de esquemas que conciben al espacio desde una perspectiva relativa, Según ésta, el espacio absoluto no existe en sí con independencia de los objetos y de las relaciones que se establecen entre ellos. Cada sistema de objetos y relaciones constituye, pues, su propio espacio de lo que resulta una noción de espacio multivariado y multifacético, adaptado a cada circunstancia espacial (Harvey, 1969). Ello lleva a distinguir, en el terreno concreto de nuestra ciencia, diferentes ámbitos espaciales según los objetos, relaciones y actividades que se aborden: espacio económico, político, rural, urbano, de los transportes y de las comunicaciones, etc., cada uno con su lógica, sistema de coordenadas y demás variables espaciales. Cada uno de estos sistemas espaciales y el conjunto de relaciones en ellos existente puede abordarse, a su vez, desde una perspectiva funcional o analítica, de lo que resulta estructuras de elementos, funciones y relaciones, o desde la intencionalidad última que configura esos sistemas, lo que lleva a la concepción del espacio como «producto social», noción tan querida de la Geografía Radical (Lacoste, 1976).

Por último, es cada vez más frecuente una visión semiótica o existencial del espacio geográfico, que aborda el estudio de éste como un conjunto de imágenes y valores, íntimos y cotidianos, con claras connotaciones simbólicas. Es el espacio vivido y directamente percibido, que configura la imagen que tenemos de él, y según la cual se establece el comportamiento humano respecto al medio. Es el llamado «espacio subjetivo», de tantas implicaciones en los modernos estudios de nuestra ciencia en cuanto, como ha dicho Boira 
(1922:14), supone «otra forma de democratización del saber espacial que no debe de ser menospreciada».

Todas estas nociones son consecuencia, como ya hemos visto, del desarrollo cognitivo del individuo, de su propia experiencia y de los esquemas propios de su cultura que, en conjunto constituyen las coordenadas que le permiten desenvolverse, comprender y actúa sobre un determinado medio. Pero, todas ellas interactúan entre sí, facilitando o dificultando la adquisición de nuevos conceptos espaciales, por lo que es esencial aplicar las estrategias adecuadas para evitar que produzcan efectos negativos en dichos procesos de aprendizaje. Así, es esencial comprender que el espacio concreto es susceptible de descripción, mientras que el absoluto es una construcción que descansa en la explicación. Por su parte, el espacio percibido sólo se puede estudiar desde una perspectiva cognitiva, afectiva y comportamental.

\section{La estructura objetiva y las categorías del Espacio Geográfico}

Pero con independencia de las nociones espaciales que se van desarrollando en la mente humana, es preciso también analizar objetivamente el contenido espacial que se pretende trasmitir y aprender. Las discusiones sobre el concepto de espacio en Geografía son muy antiguas y van íntimamente ligadas a las múltiples definiciones que se han dado de esta ciencia. Ya nos hemos referido a la ambigüedad intencionada con la que se tratan ciertos términos: lugares, paisajes, territorios o espacios propiamente dichos, pero con independencia de ello, podemos intentar sistematizar unos elementos básicos que permiten definir el sentido que ese espacio geográfico tiene en nuestros días.

Lo primero y más esencial es que el espacio sólo es geográfico en relación con el hombre. Ciencia de las relaciones entre éste y su entorno, el espacio sólo puede tener una dimensión geográfica si se aborda desde una perspectiva antrópica. Incluso el estudio del medio natural, reservado a la Geografía Física y a las restantes Ciencias de la Naturaleza, debe hacerse, si se pretende geográfico, teniendo en cuenta esta dimensión humana: la de escenario para la acción del hombre, y más aun en el momento presente, en el que el medio am- 
biente se ve perturbado por el hombre cada vez más y en mayor medida.

Desde esta perspectiva, el espacio geográfico es, ante todo, un recurso (Dollfus, 1976:39). Como tal ofrece unas potencialidades a la acción humana y establece unas limitaciones a la misma. La acción humana sobre el medio geográfico, título de una conocida obra de George (1968), es la de aprovechar al máximo las potencialidades e ir venciendo las limitaciones, en una permanente relación dialéctica que va configurando sucesivos escenarios espaciales. Colonización, explotación, bonificación, ordenación, regionalización, etc., no son más que procesos que van configurando esos nuevos escenarios, con el concurso de las innovaciones tecnológicas y las revoluciones culturales. Así, durante siglos, esa acción antrópica sobre el espacio geográfico estuvo marcada por la necesidad de un mejor aprovechamiento de las potencialidades: energía, trabajo, transportes, materias primas, en sucesivas y crecientes innovaciones culturales y tecnológicas. Hoy día, por el contrario, el gran problema del espacio geográfico es una cuestión de límites: deseconomías, externalidades, efecto rebosamiento, congestión, explosión demográfica, etc. debido precisamente a la existencia de un modelo de crecimiento ilimitado en un mundo necesariamente limitado, máxima genérica del ecologismo contemporáneo (Daly, 1989) que tanto ha influido en la definición de los actuales modelos de desarrollo sostenible. Cuando, como en el momento presente, estos estrangulamientos se producen, el modelo existente entra en crisis, los cambios se aceleran y la revolución cultural sustituye a la simple innovación tecnológica. Por ello, para Ester Boserup (1981:13): "la historia de la Humanidad puede verse como una larga serie de cambios tecnológicos».

El espacio geográfico es, pues, un espacio dinámico y de procesos. Pero también lo es de formas y estructuras. Cada proceso, o cada fase del mismo, genera unas determinadas formas espaciales, que actúan como referentes de nuevas fases. De la primitiva morfología de un medio natural no humanizado a la estructura urbana de una gran metrópoli contemporánea puede seguirse la huella de sucesivas transformaciones y de múltiples procesos. Estas estructuras espaciales permiten distinguir y dividir distintas unidades espaciales, según los procesos que las han dado lugar o según criterios puramente taxonómicos: cuencas, regiones, naciones, zonas, paisajes, pueblos, ciu- 
dades, etc., aunque pensamos que la mejor forma de abordar su estudio, es según los distintos tipos de actividades, que el hombre realiza en su medio respectivo.

Según esto, y obligados a sistematizar, podemos distinguir cuatro tipos de actividades principales que el hombre realiza respecto a su medio: ocupación, explotación, ordenación y comunicación. El recurso espacial lo es, para la sociedad y para el hombre, en cuanto soporte de estas cuatro necesidades, o al menos de alguna de ellas, que toda persona o grupo humano necesita solucionar para su normal desarrollo. La primera, más inmediata y elemental es la ocupación del espacio por el grupo, lo que posibilita su habitabilidad, vivienda y supervivencia. Estas son las transformaciones primarias que el hombre introduce en su espacio, producto de múltiples procesos, demográfi$\cos$ y sociales principalmente, y que se plasma en numerosas formas de poblamiento desde la cueva al rascacielos, o desde la aldea a la gran metrópoli. Su expresión básica es la densidad, bajo sus diversas formas, pero siempre manteniendo una relación entre población y espacio.

La segunda actividad del hombre sobre su medio es la explotación de este último, que evidencia directamente el mencionado carácter de recurso que éste tiene para áquel. Superada la larga etapa paleolítica, mal llamada depredadora a estos efectos, en la que los seres humanos constituían un elemento más del medio natural, y como tales estaban sometidos a los ciclos del ecosistema, la acción del hombre se encamina básicamene a utilizar los elementos de la Naturaleza en beneficio propio, es decir, a «explotarlos», en una constante lucha por evitar y anular los frenos del sistema natural. Los procesos de explotación antrópico del medio son diversos, pero la mejor expresión de su impacto transformador sobre el mismo en su intensidad, entendiendo por tal en sentido amplio, el grado de rendimiento buscado por unidad de superficie y, como consecuencia de ello, el impacto del tipo de explotación correspondiente. Así, la tradicional disyuntiva intensiva-extensiva propia de las actividades agropecuarias puede aplicarse también a otras formas de explotación económica, según su grado de incidencia espacial.

Ocupación y explotación, actividades íntimamente relacionadas en la práctica, no se producen de forma arbitraria, sino según un determinado comportamiento racional. La tercera actividad del hombre 
sobre su espacio es, pues, un proceso de ordenación. Los elementos de la acción humana, al igual que las formas generadas por ésta, responden a una cierta lógica de distribución y localización, lo que no quiere decir que deban seguir necesariamente unas normas rígidas de planificación o programación. El instrumento básico de este proceso es la región y la regionalización geográfica desde las múltiples perpectivas, que dichos conceptos pueden tener: región homogénea, funcional, polarizada, histórica, física, etc. El carácter de las divisiones de la superficie terrestre es un tema de larga tradición en Geografía, desde los criterios hidrográficos de Buache, a los de polarización, pasando por la región fisiográfica o la urbana (Vila, 1980:14), pero siempre con el objetivo de descubrir y apreciar una «lógica» en la distribución espacial de los fenómenos geográficos.

Por último, el espacio geográfico es, para el hombre, un ámbito de circulación, comunicación y movimiento, actividades esenciales del mundo moderno, dinámicas por naturaleza, fluidas y cambiantes, que confieren al espacio una dimensión polifacética y multivariada, que en el momento presente está adquiriendo enormes proporciones (Arroyo, 1987). En este terreno la acción del hombre sobre el espacio depende de los medios empleados para la comunicación y de su funcionalidad: transporte terrestre, marítimo, aéreo, circulación de mercancías, personas o ideas, comunicaciones por cable o por ondas, etc., que pueden llegar, incluso a proporcionar la imagen de espacialidad (Bakis, 1985) desde el momento que la comunicación puede llegar a ser instantánea, es la comunicación en «tiempo real», objetivo prioritario de las telecomunicaciones contemporáneas, reduciéndose así la fricción de la distancia a un valor igual a cero, al menos teóricamente. Por ello, la relación espacial que permite medir esta actividad es la distancia/tiem po/coste, completada, por lo que al transporte se refiere, por la de peso/coste/velocidad. Todo ello, bajo específicas categorías espaciales como la posición, accesibilidad, conectividad, nodalidad, etc.

Destrezas y capacidades espaciales.

El conocimiento procedimental en Geografía

Pero todas estas nociones sobre la naturaleza y concepto último del espacio geográfico y las diferentes actividades que conllevan, sólo 
son posibles porque todo individuo posee unas determinadas capacidades espaciales, diferentes según condiciones y circunstancias, que se desarrollan con la experiencia y el aprendizaje y que permiten el conocimiento, la supervivencia y la acción de las personas en el medio que le ha tocado vivir. El mismo Vidal de la Blache gustaba de recordar que: «los campesinos son, a menudo, mejores geógrafos que los geógrafos mismos», en clara referencia a esas capacidades que el campesino tiene sobre el ciudadano, o mejor aun, la primacía de las destrezas empíricamente asimiladas por un agricultor experto, pues le va en ello su supervivencia, respecto al conocimiento científicamente elaborado y académicamente formalizado de un geógrafo profesional. En la misma línea, aunque en sentido contrario, Pinchemel (1982:20) puso de manifiesto como "algunas investigaciones recientes parecen mostrar que se da en el llamado hombre de la calle una incapacidad considerable para actuar con eficacia en un contexto espacial». De esta forma resulta paradójico que, mientras, por un lado, aumenta el nivel cultural medio de la población, se puedan perder, por otro determinadas capacidades y habilidades que eran comunes en otros estadios culturales precedentes, y que, a todos los efectos, podemos considerar como menos evolucionados y complejos. Podría pensarse que se trata de la sustitución de unas capacidades por otras, consecuencia de la demanda cultural de las nueva forma de vida urbana, respecto a la antigua rural. De ser así, nos encontraríamos con la simple evolución de saberes colectivos condicionados por el cambio histórico correspondiente. Tal sería el caso, analizado por Hauser (1951: I, 19) de la falta de la capacidad de observación ambiental del pintor-cazador del Paleolítico, autor de un arte extraordinariamente naturalista, respecto al geométrico del agricultor neolítico al que su nueva actividad obligó a desarrollar el pensamiento abstracto en detrimento de la observación instantánea, pero no creemos sea el mismo caso, pues de lo que ahora se trata es de la pérdida de una capacidad crecientemente demandada por nuestra sociedad: orientarse, leer un mapa, valorar las distancias en tiempo, etc., son destrezas imprescindibles para entender el mundo de nuestrtos días, tanto o más que lo fuese en el pasado. Por ello pensamos que se trata más de un problema de educación y de aprendizaje o mejor, si se nos permite, de desaprendizaje.

De esta forma pensamos que sólo una correcta educación geográfica puede ayudar a recuperar esas destrezas espaciales que en el 
hombre de nuestro tiempo empiezan a ser carencia notable. De lo que se trata es de potenciar esa capacidad que Vidal intuía en las gentes del campo, y cuya perdida lamentaba Pinchemel en los de la ciudad. Ninguno de los dos llegaron a definir de que se trataba y a qué se debía. Nosotros, por nuestra parte, pensamos que uno y otro se están refiriendo a lo que, según la moderna psicología de la instrucción, podríamos llamar procedimientos espaciales, y cuya pérdida podemos atribuir a la manera, excesivamente, formalizada en que se realiza hoy día el aprendizaje de conceptos y capacidades espaciales, frente a la más directa y personal dominante en las sociedades que están más en contacto con el medio natural.

En definitiva se trata de precisar cuales son las capacidades y destrezas propias del saber geográfico, lo que diferencia, o debiera diferenciar, al geógrafo de cualquier otra persona que no lo es cuando uno y otro analizan el mundo en que viven. Esa diferencia no es sólo el nivel de conocimiento teórico que el primero tiene de dicho mundo, sino la forma de enfrentarse al mismo, de interpretar los fenómenos que ocurren en él. Pues bien, esa diferencia que resulta evidente en lo relativo al conocimiento conceptual o teórico, lo es menos en lo que se refiere a las capacidades y destrezas espaciales de carácter procedimental.

En lo referente a la Geografía, dichas destrezas o conocimiento procedimental pueden agruparse en dos tipos: de carácter genérico y de carácter específico o puramente geográficas. Las primeras son compartidas con otras disciplinas y áreas de conocimiento, y entre las más significativas podríamos citar la observación, la visualidad, la graficidad, la cuantificación, etc. Pero son las segundas las que aquí más nos interesan. Esas otras capacidades o destrezas espaciales son esencialmente tres y constituyen la base de lo que podríamos denominar el saber espacial, de carácter primordialmente procedimental.

a) En primer lugar la identidad espacial. El medio en el que vivimos, habitamos, explotamos y recorremos, contribuye además a configurar nuestra propia identidad como individuos o colectividad. La primera expresión de que el hombre ha tomado esa conciencia del «lugar» en el que se encuentra y que, en cierta manera, se identifica con él, que lo individualiza y lo designa con nombres propios, tal como se relata en el mismo Génesis. Esta es la razón última y transcendente de la toponimia. Este hecho, aparentemente trivial, es uno 
de los aspectos de mayor interés para la Geografía, del que encontramos muestras en numerosas ocasiones: desde el mismo sentido de teritorialidad que tenemos los seres humanos, al igual que otros muchos seres vivos, hasta la sublimación de los nacionalismos y del mismo patriotismo, pasando por los innumerables ejemplos de personal indentificación con un paisaje, de «amor a la tierra» y a sus imágenes más representativas, que pueden convertirse en símbolos de la propia personalidad. Impulso primario que convierte a montañas, valles, árboles o campanarios en valores inconográficos y dan sentido y razón a una sociedad. De la misma forma, por ejemplo, el contorno del mapa de un país puede llegar a ser el símbolo del mismo. Todo ello lo saben muy bien los emigrantes que, junto a otros desclasamientos, se ven también privados de ese sentido de identidad territorial.

b) Una segunda capacidad espacial, plenamente geográfica, es el sentido de localización, distribución y medida que poseemos los seres humanos y que nos permite situarnos en el espacio, nosotros mismos y los objetos de nuestro entorno, medir sus elementos, magnitudes y distancias, ordenar nuestra intervención y distinguir esos objetos espaciales según su volumen, valor, densidad, jerarquía, etc., estableciendo así las relaciones pertinentes. A diferencia de la anterior categoría, esta capacidad de localizar o distribuir es ya plenamente racional, pues supone una comprensión previa del medio y de las posibilidades que el hombre o la sociedad tienen de intervenir en él. La denominación toponímica identifica sólo a aquellos hitos o enclaves individualizables que van a actuar como referentes de situación, pero no de distribución, extensión o cantidad. Para ello, las necesidades de la cognición ambiental obligan a valorar, medir y jerarquizar los elementos que el hombre encuentra en su entorno, utiliza y aprovecha, dando lugar a todo un sistema de categorías perceptivas puramente empíricas, reflejo directo e inmediato, como decíamos, de las relaciones del hombre con su medio.

c) Por último, la tercera categoría o capacidad espacial es la representación-interpretación de los hechos espaciales, sobre un plano, mapa o simple dibujo, mediante la utilización o lectura del lenguaje correspondiente: descriptivo, sistemático o icónico, y según las propias circunstancias culturales de cada individuo o colectividad. Recuérdese que, para algunos autores, la cartografía precedió a la escritura entre los inventos del hombre (Zumthor, 1933: 304). Esta 
capacidad de representación e interpretación no es más que la plasmación gráfica de los mapas mentales de cada individuo, que pueden así intercambiarse y convertirse en instrumento de comunicación de las experiencias espaciales. Ello se pone claramente de manifiesto con la cartografía espontánea, expresión de la capacidad humana de representación espacial y de la necesidad de establecer un código inmediato y analógico de comunicación para transmitir la propia experiencia espacial.

Estas tres capacidades posibilitan la actividad de los seres humanos sobre el medio natural, sus conocimiento, apropiación y modificación. En la configuración de todas estas nociones y capacidades espaciales se dan factores innatos y adc uiridos, en relación con la personalidad, cultura y experiencia espac al de cada sujeto, de forma que, en la práctica, pueden presentarse situaciones muy diferentes. En la sociedad preindustrial predominaba una concepción espacial directa e inmediata, pero que quedó oculta por la racionalización matemática y decimal del mundo moderno, aunque se conserva en la percepción espontánea de cada individuo. Sin embargo, rara vez se pone de manifiesto esa disyuntiva en el aprendizaje espacial y se valora como geográfico sólo la perpectiva matemáticamente formalizada, lo que desde el punto de vista científico parece evidente, pero no lo es tanto desde el educativo. Además, las contradicciones de nuestro modelo de industrialismo, la reacción que nuestra época experimenta frente a los excesos de racionalización y matematización y la creciente valoración de las percepciones personales y subjetivas, de la perspectiva local, de lo difuso, lo diverso y lo pequeño (Sumacher, 1973) frente al monolitismo de la sociedad industrial, confieren un valor añadido a las formas de conocimiento e interpretación del espacio de épocas pasadas y sugieren su utilización como técnica aprendizaje de dichas capacidades espaciales. Es lo que intentaremos sistematizar a continuación, en relación con las tres capacidades citadas.

\section{La toponimia como expresión de la identidad espacial}

En efecto, la identidad espacial o territorial tiene un buen exponente en la toponimia. La forma como una colectividad da nombre a los hechos espaciales de su entorno: accidentes, lugares, parajes par- 
ticulares o calles, etc. es una excelente muestra de que se ha establecido una doble relación entre las gentes y el territorio: por un lado un deseo de apropiación de los primeros, respecto a los segundos, y a la vez, una personificación del territorio que se individualiza y adquiere señas de identidad para la colectividad que lo habita y lo explota. La designación de nombres de lugar tiene un carácter esencialmente utilitario, en cuanto los habitantes de un determinado territorio tienen necesidad de distinguirlos (Rostaing, 1945:6). En el mundo rural, una primera categoría de topónimos está en relación con fenómenos del mundo físico en cuanto estos pueden caracterizar al medio desde una perspectiva humana: umbría y solanas, fuentes, valles y collados, por ejemplo. Igualmente, las referencias cardinales están en directa relación con la percepción, del movimiento del sol en la mayoría de los casos: levante, poniente, mediodía, y del soplo del viento en el resto: cier$z o$, solano, tramontana, mestral, ábrego, etc. Más evolucionadas son las denominaciones de carácter hagiotoponímico: patronos o santos del lugar, buscando la protección de lo transcendente. Sin embargo, las referencias astronómicas para denominar a las coordenadas geográficas suponen un principio de abstracción escasamente compatible con una visión cotidiana del entorno. Similar planteamiento es la forma utilizada comúnmente para la toponimia urbana con nombres propios de personajes o acontecimientos colectivos de carácter simbólico. Sin embargo, frente a estos sistemas de identificación territorial, todavía comunes en la mayoría de sociedades con ciertas raíces históricas, se va generalizando una toponimia de carácter numérico o geométrico, que responde a valores de pragmatismo espacial y del que son buena muestra la denominación de las redes de comunicaciones, las referencias a puntos quilométricos o la forma de designar a las avenidas y calles de muchas ciudades americanas. Sin embargo, resulta evidente que la toponimia tradicional, de raíz histórica, refleja mucho mejor las peculiaridades espaciales que permiten comprender un territorio y supone otra forma más adecuada de entender el espacio, en definitiva.

\section{La medición empirica predecimal}

También en la foma de medir el territorio, consecuencia directa de la capacidad de distribución y localización de los seres humanos, 
se puede observar un acusado contraste entre las medidas tradicionales y las decimales. La adopción del sistema métrico decimal fue un elemento de modernidad exigido por las transformaciones de la industrialización y de la revolución liberal, y que, al igual que el establecimiento de registros estadísticos fiables, marca la diferencia entre una dilitada etapa preindustrial y la génesis del mundo moderno. Como tal mecanismo de modernización, el sistema decimal fue la concreción de unos principios racionales, universales y positivos, como exigían los nuevos tiempos, al terreno de la medición de superficies, volúmenes, masas y otras diversas magnitudes, buscando «poner orden» en un sistema caracterizado negativamente por la diversidad de unidades en una misma medida (almud, fanega, quarta, etc.), por la variedad de medidas en una misma magnitud (fanega, aranzada, obrada) y por la complejidad y el caos de los múltiplos y divisores, además de la variabilidad según comarcas y regiones o incluso dependiente de la calidad y tipo del producto que se medía (calidad de la tierra, densidad del líquido, etc.). Por ello, se definieron unas unidades universales y teóricas sin ningún nexo con la experiencia y el quehacer cotidianos, como había ocurrido hasta la fecha y, a partir de ellas, se establecieron los correpondientes múltiplos, divisores y equivalencias, siguiendo un razonamiento lógico $\mathrm{y}$ matemático $\mathrm{y}$ siempre según la base decimal previamente seleccionada. No obstante, se pretendió que las nuevas unidades tuvieran una base real, para que fueran útiles «a todos los pueblos en todos los tiempos», como decía la Ley francesa de 1795 que promulgó su implantación, pero en relación a magnitudes físicas formuladas matemáticamente. Así, las medidas de longitud y superficie, que aquí más nos interesan, se definieron respecto a magnitudes terrestres, pero bajo la perspectiva astronómica y matemática -recuérdese la primitiva definición de metro- y no repecto al espacio terrestre cotidiano e inmediato, como venía ocurriendo hasta entonces.

No se puede negar la utilidad y adelanto que el establecimiento de este sistema, y sobre todo su universalidad, ha supuesto para las transformaciones del mundo moderno. Pero su adopción y necesaria generalización arrinconó primero y desplazó después a las formas métricas utilizadas hasta entonces. A diferencia del nuevo sistema, la tradición métrica se basaba en principios estrictamente empíricos, como correspondía a otro orden de valores. Las medidas se habían 
ido configurando según las necesidades. La unidad básica siempre tenía una referencia real y tangible del mundo cotidiano, por lo que variaba de una región a otra. Sus múltiplos y divisores no seguían una regla fija, y en todo caso, prevalecían criterios sexagesimales o «por cuartos y mitades» y casi nunca decimales (Camarero, 1989:483).

Pero lo más importante, desde una perspectiva perceptiva o ambiental, es que los sistemas tradicionales de medidas son reflejo directo y sugerente de las relaciones del hombre con su entorno y, tal como corresponde a la práctica empírica de la sociedad rural que les dio lugar, expresión de la adaptación del comportamiento del primero, respecto a las normas y características del segundo. Por eso, responden a la misma concepción del espacio, directa e inmediata a la que nos referíamos anteriormente. Por el contrario, la métrica decimal simboliza todo lo contrario: la pretensión humana de dominio sobre la Naturaleza tan propia de la revolución industrial, el deseo de someter el medio natural al cosmos racional de un sistema apriorístico matemáticamente formalizado. Por ello tampoco es casual que fuera en la Francia Revolucionaria, racionalista e ilustrada, donde se acuñara por vez primera, como tampoco lo es que fuera en el mundo anglosajón, donde prevaleciera aquel otros sistema de medidas más acorde con la tradición empírica británica.

En una primera fase del proceso cognitivo el propio hombre es frecuentemente la unidad de medida más utilzada lo que nos obliga a recordar la famosa frase de Protágoras: el Hombre medida del Universo. Desde el canon de Policleto al antebrazo del anónimo arquitecto de las pirámides egipcias, la anatomía humana es una excelente fuente de unidades de medición, como ya viera Kula (1980): la altura media de cualquier persona, el grosor del brazo, muslo o cintura, su capacidad de trabajo diaria, etc., son dimensiones frecuentemente tomadas como referencia de unidades de medida. En otras ocasiones también se empleaban objetos próximos de la vida diaria, como frutas, monedas y otros instrumentos cotidianos que eran tomados como tales unidades de referencia.

Pero cuando se trata de medir una magnitud continua y extensa, como una zona o área, las dificultades aumentan. Así, la percepción humana es fácilmente sensible a la imagen de distancia lineal, pues, como sabemos, la relación entre distancia, tiempo y velocidad es una de las ideas espaciales más inmediatas percibidas por el individuo en 
cohrencia con la necesidad, frecuencia e inmediatez del traslado y del transporte. Además esa distancia lineal es fácilmente mensurable extendiendo conceptos antrópicos, como dedos, pies o pasos, o algo más elaborados, pero siempre en relación a una capacidad humana: vara, tiro de ballesta, de piedra o de arcabuz, jornada, etc. Por ello, siguiendo con el mismo razonamiento, es lógico que en este segundo caso se recurriera también a otra variable similar, el mismo trabajo humano, como elemento de medición y, en consecuencia, de valoración espacial. De esta forma, la superficie que podía ser trabajada por el campesino y sus animales en una jornada fue evolucionando hacia una unidad de superficie -recuérdese, a estos efectos, la leyenda de la fundación de Roma- lo cual supone una visión del espacio mucho más operativa e inmediata, como recurso y objeto de explotación por el hombre y elemento directo de su intervención. En otras ocasiones, la medida superficial de la tierra dependía de su funcionalidad, es decir, de su capacidad para dar cabida a una determinada unidad de semilla, insistiendo en la misma línea de razonamiento de concebir el epacio como una suerte de recurso por y para el hombre (Ferrer, González, 1996).

\section{La cartografía pregeométrica}

Por último, es tal vez en relación con las representaciones cartográficas, donde se percibe con mayor claridad el cambio de los conceptos espaciales derivado de la evolución cultural. Pues en propiedad, hay que considerarlas como una forma de lenguaje gráfico o código de comunicación. A partir del siglo XVI estas representaciones son una forma de exteriorización de los conceptos de la cartografía ptolemaica de diseño matemático, más o menos perfeccionada y que sería la que terminará imponiéndose, pero anteriormente predominan unos mapas empíricos, prácticamente espontáneos, sin ninguna sujeción a criterios de perspectiva, escala o proyección, reveladores, no obstante, de las cogniciones espaciales de sus autores y de la colectividad a la que iban dirigidos. De este tipo de mapas, conocidos vulgarmente como «no profesionales» tenemos numerosas muestras en archivos y cartotecas, algunas con extraordinario valor icónico y simbólico. 
En todos ellos, es mucho más frecuente una visión del espacio como jerarquía de valores que como sistema de magnitudes, lo que se pone claramente de manifiesto en representaciones planas y sin ninguna perspectiva, en las que el tamaño de figuras y objetos está más en relación con la jerarquía social, que con su magnitud real. También son frecuentes croquis simbólicos en los que se exagera aquellos objetos a los que se les quiere dar más valor, ignorándose otros, que una cartografía más «objetiva» no podría eludir. En todos ellos predomina un estudio concreto del entorno, de carácter descriptivo-narrativo, más que la forma genérica de interpretación-explicación propia de la cartografía geométrica. Así, para Zumthor (1993: 305), cada punto de estos mapas contienen todos los conocimientos del grupo sobre los hechos representados.

A este respecto, un ejemplo significativo lo tenemos en el estudio sobre los mapas de ilustraciones de este tipo que acompañan la obra geográfica de Tomás López (Caro, 1989:118), uno de los mejores ejemplos de esta cartografía no profesional como es sabido. En dicho estudio se agrupa y distingue dichos mapas en cuatro categorías que recuerdan algunos de los estadios evolutivos del conocimiento piagetiano. Un primer grupo lo constituyen los mapas circulares y cerrados, en los que el lugar que ocupa el relator es el centro de la representación, es decir, son de formato egocéntrico. Son los mapas de configuración más antigua, análogos a los utilizados comúnmente en la Edad Media, en los que las únicas relaciones visibles son de lejanía o proximidad con el centro de la representación, por lo que podríamos definir como topológicos.

Junto a éstos, un segundo grupo, que el autor del estudio define como «naturalistas» se configura con grupos descoordinados de objetos coordinados entre sí. La superficie así representada aparece constituida por estructuras con proyección exclusivamente interna, pero sin ningún tipo de relaciones espaciales entre ellas. Un tercer tipo, son representaciones pictóricas más propiamente dichas, con un horizonte común para toda la superficie cartografiada, lo que supone la existencia ya de una cierta idea proyectiva y que, por lo general, están orientados a levante. Por último, otro conjunto, el menos numeroso, tiende hacia la abstracción y podrían considerarse ya como mapas pregeométricos.

De esta forma, en un mismo cuerpo cartográfico, aunque debido a

$$
-536-
$$


muy diversas manos como es la colección de mapas que Tomás López recibió de los párrocos de los numerosos pueblos encuestados, se pueden distinguir, con las diferencias lógicas de cada caso, los estadios fundamentales de representación espacial que años después también viera Piaget, aunque desde una perspectiva muy distinta.

Por el contrario, la cartografía geométrica responde a otra concepción totalmente diferente. Al igual que con la métrica decimal, se busca una representación lo más exacta posible, según principios y analogías estrictamente racionales, como pueden ser la escala, los diversos sistemas de proyección, las coordenadas y demás líneas y vértices de representación, etc. Todo ello supone un instrumento imprescindible para el análisis y el conocimiento espacial, sobre todo, a partir de la revolución industrial, cuando el mundo quedó sometido a un cosmos racionalista y mecanicista, pero a la vez es un lenguaje de comunicación muy abstracto, que requiere un entrenamiento previo para su uso, lo que normalmente se olvida a la hora de programar su aprendizaje y comprensión. Y lo más importante es que, como la toponimia numérica o la medición decimal, responde a una cosmovisión racionalista y a una concepción del medio acorde con la época y con los valores que le son propios, pero ignora una percepción del espacio más intuitiva y empírica que ha sido la común en épocas pasadas y lo es todavía en estadios anteriores del conocimiento.

\section{Procesos de enseñanza-aprendizaje del espacio geográfico}

De esta forma llegamos al punto final de esta reflexión: ¿cómo organizar todos estos conocimientos de forma que puedan constituir la base de un auténtico aprendizaje geográfico? En síntesis, hemos visto que éste debería incluir, al menos, nociones y capacidades espaciales, tanto de carácter conceptual como procedimental, abstractas y concretas y a diversas escalas y niveles. El conocimiento geográfico incluye, asimismo, el correcto análisis de las relaciones Hombre-Medio y de las actividades humanas que ocupan, explotan y ordenan el espacio, de los procesos inherentes a las mismas y de las formas espaciales a las que dan lugar. Todo ello, teniendo en cuenta la evolución epistemológica de esta ciencia que ha pasado por diversos estadios, de ser una disciplina descriptiva de situaciones únicas e irrepetibles, 
a las generalizaciones explicativas y al análisis cuantitativo, sin olvidar la creciente perspectiva social.

Pues bien, creemos que precisamente esa evolución es el mejor método de enseñanza de la Geografía, la mejor forma de convertir la ciencia en disciplina. Reproducir el proceso de formación histórica de la Geografía puede ser un buen sistema y una excelente guía para diseñar su aprendizaje en nuestros días. Así, en sus primeras etapas, la Geografía está presidida por el descubrimento del espacio terrestre y su correspondiente descripción después de fijar la localización de las nuevas tierras descubiertas, y en buena medida este proceso de descubrimiento de espacio, es asimilable al primer impulso de conocimiento que experimenta cualquier ser humano al tomar contacto con su entorno. Hasta el siglo xviII, con la dinámica propia de la centuria, no se produce la preocuapción por la explicación de los hechos geográficos que, hasta entonces, eran simplemente descritos y localizados, lo que condujo al nacimiento de una Geografía científica, obra de Humboldt y Ritter, como es de sobra conocido. Por ello, si la explicación supuso un estadio histórico posterior y más elaborado en el proceso de conocimiento del espacio geográfico, de sus formas y procesos, igual ha de ocurrir con su aprendizaje en nuestros días. Pero los fenómenos geográficos, como cualquier otro tipo de poceso social, difícilmente pueden someterse a un sólo orden de explicación, y ello se vio muy bien en la evolución del pensamiento geográfico, muy sensible a a ideología y cosmovisión predominante en cada época. Así, mejor que de explicación es preferible hablar de interpretaciones de los fenómenos geográficos, lo que frecuentemente da lugar a polémicas: determinismo o posibilismo, regional o general, analítica o radical, etc. buscando así que la insatisfacción del debate epistemológico pueda enriquecer el correspondiente proceso de enseñanza-aprendizaje. De esta forma, mantener esta secuencia permite adaptarse tanto a las exigencias congnitivas del individuo, puestas de manifiesto en diversas teorías de aprendizaje, sobre todo en la de la elaboración de Reigeluth (Aparicio, 1992), como a la estructura lógica de la disciplina que se intenta aprender, tal y como ésta se ha ido configurando en el pasado.

Teniendo en cuenta todos estos elementos, podemos elaborar un modelo del aprendizaje geográfico en el que se relacionen las secuencias cognitivas del sujeto con la estrucura propia de la disciplina, y 
que a rasgos generales pueden descomponerse en cuatro estadios sucesivos o complementarios.

El nivel inicial y más elemental correspondería a la descripción que es propia de la Geografía clásica. Aspecto tantas veces criticado por memorístico y escasamente significativo, la descripción es un elemento esencial del conocimiento geográfico, tal como lo expresa la misma etimología de nuestra ciencia. Otra cosa es que el abuso del mismo, conduzca a una acumulación de datos inoperantes e inútiles, o que todo el conocimiento geográfico se pretenda reducir sólo a este aspecto. Pero si se soslayan estos riesgos y se complementa la descripción con explicaciones elementales, resulta una exigencia didáctica ineludible. La Geografía descriptiva, correctamente planteada, permite la elaboración de unos primeros esquemas conceptuales de lugares, accidentes y hechos concretos, de los que el individuo tiene percepción y experiencia directa y que, si están debidamente seleccionados, son imprescindibles para posteriores formas de análisis y explicación. Como en su día señalara el mismo Ausubel (Pozo, 1989:211), el aprendizaje receptivo de hechos y accidentes, propio de la descripción geográfica, no tiene que ser necesariamente repetitivo o memorístico, siempre que tales accidentes hayan sido previamente seleccionados de acuerdo no sólo a la lógica de los contenidos, sino también en relación a las necesidades de los alumnos. Lo que, en definitiva, va a permitir la inclusión y comprensión de nuevos conocimientos sucesivos. Una forma de fomentar el desarrollo de lo que Marina (1955:139) llama la memoria inteligente del alumno.

Pero la descripción clásica descansa, por lo general, en una concepción absoluta del espacio, de existencia real, tridimensional y que incluye, tanto el contenido como al continente. Esta noción, como ya hemos dicho, sólo abarca una perspectiva de las múltiples con las que pueden abordarse el estudio del espacio geográfico. Además, esta misma visión conduce a la idea de unos procesos y formas espaciales únicos e irrepetibles, de difícil generalización y normalización explicativa, lo que nos lleva rápidamente a un callejón sin salida. Todo lo más, es posible explicaciones de carácter idiográfico, «excepcionales» las llamó Schaefer (1953), mediante analogías y similitudes externas.

Sin embargo, la mayoría de los fenómenos y formas geográficas exigen otro tratamiento para su comprensión y aprendizaje. Ello obli- 
ga a un segundo nivel de aprendizaje para lo que conviene recurrir a otras formas de análisis geográfico, a otras estrategias de aprendizaje y, sobre todo, a otras nociones y percepciones espaciales. La idea de un espacio geométrico relativo, es más propia de una sociedad compleja, en la que los procesos predominan sobre las formas y cada actividad humana se mueve en unas coordenadas distintas. Esta noción exige un superior nivel de abstracción y una cognición espacial más compleja, pero ello no quiere decir que no se den en cada individuo suficientes condiciones objetivas para su aprendizaje, siempre y cuando se utilicen las técnicas y estrategias adecuadas. Entramos con ello en el ámbito teórico de la llamada Geografía cuantitativa que, si a efectos epistemológicos, se presentó en su día como las antípodas de la Geografía clásica, puede suponer, desde una perspectiva docente, una fase subsiguiente de la misma. La distorsión que en el discurso científico de la Geografía supuso la aparición, a principio de la década de los sesenta, de las teorías analíticas y cuantitativas, que Peter Gould definió como la New Geography, estuvo provocada en gran medida por la utilización de dos lenguajes espaciales diferentes, que se correspondían con las distintas nociones aludidas, por lo que casi nunca llegaron a entenderse.

Además, la preocupación esencial de esa Geografía «nueva», en su día, era alcanzar una explicación global para los fenómenos geográficos que permitiera, incluso la elaboración de leyes generales, para lo que naturalmente se requería otra noción de espacio que no fuera única e irrepetible como la de la Geografía tradicional. Todo ello ya tuvo su discusión epistemológica, su momento de aceptación y de crítica, y lo que es más importante, dejó un legado racionalista adecuado para abordar el aprendizaje de las nuevas dimensiones espaciales del mundo moderno. Así, análisis, explicación y cuantificación conducen al aprendizaje y compensión de una noción relativa del espacio en el que estrucuras, sistemas, modelos, etc., debidamente formalizados constituyen el núcleo esencial de la explicación geográfica y completan la dimensión estrictamente territorial de la misma.

Las aportaciones científicas de la Geografía analítica: relatividad del espacio geográfico, aplicación de las nociones de sistema, estructura, modelo, conjunto, etc. a procesos y formas geográficas, se convierten así en estrategia de aprendizaje de esa nueva dimensión del espacio geográfico, tanto por lo que respecta a su carácter relativo y 
relacional, como a la diversidad de interpretaciones del que puede ser susceptible. De esta forma el uso que de esas concepciones hizo la Geografía Radical de la década de los setenta permite asimismo, abordar el problema de la conflictividad del espacio social y las tensiones creadas por los deseos de uso y apropiación del mismo por clases y grupos sociales. La explicación así puede ir doblada de cierto compromiso idelógico-ecológico y permite tratar el siempre difícil tema de los valores y actitudes espacio-ambientales.

La misma finalidad cumple, por último, la perspectiva perceptiva y comportamental, con el interés particular de subrayar la dimensión afectiva de los «espacios personales». Como ya dijimos en su momento, las primeras cogniciones espaciales lo son dentro del ámbito de lo cotidiano y de lo personal y, posteriormente, evolucionan hacia la abstracción y la generalización. Pero este hecho no ha sido tenido en cuenta en la enseñanza de la Geografía y del espacio geográfico, hasta que la llamada Geografía «Humanística» no ha puesto énfasis en la dimensión subjetiva de esos espacios personales, particulares e individuales.

De esta forma y junto al espacio único de la Geografía Clásica y al relativo de la analítica, cobra especial interés la noción de espacio como referente simbólico e iconográfico de las gentes que lo habitan, razón y explicación de muchos de sus comportamientos espaciales, incomprensibles desde una óptica exclusivamente racional y matemática, y razón también, en múltiples ocasiones de su misma identidad personal y social. Sólo cuando se han adquirido todas estas nociones es posible manejar correctamente las destrezas espaciales que caracterizan al conocimiento geográfico procedimental.

\section{BIBLIOGRAFÍA}

Anderson, J. R. (1983): The Architecture of Cognition. Cambrigde, M. A. Harvard University Press.

Aparicio, J. J. (1992): «La psicología del aprendizaje y los modelos de diseño de enseñanza: la teoría de la elaboración». En Tarbiya. Revista de investigación e innovación educativa, n. ${ }^{\text {os }}$. 1-2, julio-noviembre, pp. 19-44.

- (1995): «El conocmiento declarativo y precedimental que encierra una disciplina y su influencia sobre el método de enseñanza». En Tarbiya. Revista de investigación e innovación educativa, $\mathrm{n}^{\circ}$ 10. mayo-agosto, pp. 23-37.

Arroyo Ilera, F. (1987-88): «Telecomunicaciones, espacio geográfico y ordenación del territorio». En Telos. Cuadernos de Comunicación, Tecnologia y Sociedad, n. ${ }^{\circ} 12$, diciembre-febrero, pp. 14-22. 
- (1995): «Una cultura geográfica para todos: El papel de la Geografía en la educación primaria y secundaria». En Moreno Jiménez, A. y Marrón Gaite, M. ${ }^{a}$ J. (Edit.): Enseñar Geografía: de la teoría a la práctica. Madrid, Síntesis, pp. 43-57.

Bale, J. (1987): Didáctica de la Geografía en la escuela Primaria. Madrid. Morata-MEC, $184 \mathrm{pp}$.

BaKIs, H. (1984): Géographie des Telecommunications. París, PUF, 128 p.

Borra, J. V. (1992): La ciudad de Valencia y su imagen pública. Valencia, Departamento de Geografía de la Universidad de Valencia, $208 \mathrm{pp}$.

Boserup, E. (1981): Population and Technological change. A study in longterm trends. Chicago. The University of Chicago. Trad. española: Población y cambio tecnológico. Barcelona, Crítica, $358 \mathrm{pp}$.

Bunge, W. (1962): Theoretical Geography. Lund. The Royal University of Lund. Departament of Geography, 2. ${ }^{a}$ ed. ampliada 1966, $285 \mathrm{pp}$.

Camarero Bullón, C. (1989): Burgos y el Catastro de Ensenada. Burgos, Caja de Ahorros Municipal, $528 \mathrm{pp}$.

CAPel SÁez, H. (1981): Filosofía y ciencia en la Geografía contemporánea. Una introducción a la Geografía. Barcelona, Barcanova, $514 \mathrm{pp}$.

CAPel SAez, H. y URTEAGa, L. (1987): «La Geografía ante la reforma educativa». En La Geografía y la Historia dentro de las Ciencias Sociales: hacia un curriculum integrado. Madrid. Dirección General de Renovación Pedagógica. MEC, pp. 129-172.

Caro, C. (1989): «La cartografía de los no profesionales. El Diccionario de Tomás López». En Primeras Jornadas de Historia de la Cartografía. Ponencias. Madrid. Sociedad Española de Cartografía, Fotogrametría e Interpretación. Edición policopiada, pp. 118-124.

CatLInG, S. J. (1976): «Cognitive mapping: judgements and responsibilities». En Architectural Psychology, Newsletter. VI. New York.

Daly, H. comp. (1989): Economía, Ecología, Etica. Ensayos hacia una economía del estado estacionario. México. FCE.

Debasse-Arviset (1968): La Géographie a l'ecole. París. PUF.

Dollfus, O. (1976): L'Espace Géographique. París. PUF. Trad. española: El espacio geográfico. Barcelona, Oikos-Tau, 128 pp.

Ferrer Rodríguez, A. y González Arcas, A. (1996): Las medidas de la tierra en Andalucía. Madrid, Centro de Gestión Catastral y Cooperación Tributaria, Tabapress, 368 pp.

George, P. (1968): L'action humaine. París. PUF. Trad. española: La acción del hombre y el medio geográfico. Barcelona, Península, 1970, 248 pp.

Graves, N. J. (1984): La Enseñanza de la Geografía. Madrid, Apendizaje-Visor, 224 pp.

HaRvey D. (1969): Explanation in Geography. London, Edward Arnold. Trad. española: Teorias, Leyes y Modelos en Geografía. Madrid, Alianza Editorial, 1983.

Hauser, A. (1951): The Social History of Art. London, Routlege \& Kegan Paul. Trad. española: Historia social de la Literatura y el Arte. Madrid, Guadarrama, $4 .^{a}$ ed., 1971, 3 vols.

Herrero Fabregat, C. (1992): Madrid visto por los niños. Madrid, CEMIP, 128 pp.

Kula, W. (1980): Las medidas y los hombres. Madrid, Siglo XXI, 482 pp.

Lacoste, Y. (1976): La Géographie, ça sert d'abord, a faire la guerre. París, Maspero. Trad. española: La Geografía, un arma para la guerra. Barcelona, Anagrama, $160 \mathrm{pp}$.

Lynch, K. (1960): The Image of the City. Massachussets. Institute of Technology. Trad. española: La imagen de la ciudad. Buenos Aires, Ed. Infinito.

MaRInA, J. A. (1995): «La memoria creadora». En Tarbiya. Revista de investigación e innovación educativa, $\mathrm{n} .^{\circ} 10$, mayo-agosto.

Mumford, L. (1934): Technics and Civilization. Harcourt, Brace \& World, Inc. Trad. española, Técnica y Civilización. Alianza Editorial. Madrid, 1982, 4. ${ }^{\mathrm{a}}$ edición, $528 \mathrm{pp}$.

OchatTA, E. y HuerTas, J. A. (1989): «Desarrollo y aprendizaje del conocimiento espa- 
cial: aportaciones para la enseñanza del espacio geográfico». En Boletin de la Asociación de Geógrafos Españoles, n. ${ }^{\circ}$ 8, pp. 10-20.

Pinchemel, Ph. (1982): «Fines y valores de la educación geográfica». En New Unesco Source Book for Geography Teaching. Trad. española Nuevo método para la enseñanza de la Geografía.Barcelona, Teide, 1989, pp. 7-21.

Plans, P. (1967): Orientaciones sobre Didáctica de la Geografía. Madrid, Magisterio Español, $184 \mathrm{pp}$.

Pozo, J. I. (1989): Teorias cognitivas del aprendizaje. Madrid, Morata, $288 \mathrm{pp}$.

Rostaing, Ch. (1945): Les noms de lieux. París, PUF, 6. ${ }^{a}$ ed., 1965, 128 pp.

Schaefer, F. K. (1953): «Excepcionalism in Geography». En Annals of the Associations of American Geographers. Trad. española y estudio introductorio de H. Capel. Barcelona, Ediciones de la Universidad de Barcelona, 2. ${ }^{2}$ ed., 1974, 88 pp.

Schumacher, E. F. (1973): Lo pequeño es hermoso. Madrid, Blume.

Tuan, Y. F. (1974): Topophilia: A Study on Environment Perception, Attitudes and Values. New York. Prentice Hall.

Vila Valenti, J. (1980): «El concepto de región». En La región y la Geografía española. Valladolid. Asociación de Geógrafos Españoles.

WALKER, M. J. (1975): Localitation and Links. London. Blackwell.

Zumthor, P. (1993): La mesure du monde. Représentation de l'espace au Moyen Age. Ed. du Seil. París. Trad. española: La medida del mundo. Ed. Cátedra, Madrid, 1994, 422 pp.

RESUmen: Reflexiones sobre el espacio y su enseñanza. Se pretende resumir los principales problemas de la enseñanza de la Geografía teniendo presente tanto las características científicas de esta disciplina, como las necesidades del aprendizaje de los alumnos según la Psicología cognitiva. El problema esencial radica en la enseñanza del «espacio geográfico» tanto desde el punto de vista declarativo como procedimental. Para ello se resumen distintas perspectivas sobre el concepto de espacio geográfico y se sugieren procedimientos para facilitar los procesos de su enseñanza y aprendizaje.

Palabras Clave: Espacio. Didáctica. Epistemología. Conocimiento procedimental.

RÉSUME: Reflexions sur l'espace geographique et son enseignement. Il sagit de résumer les pricipaux problèmes de l'enseignement de la Géographie en tenant compte tout autant les caractéristiques de cette discipline, comme les besoins d'apprentissages des élèves d'après la Psicologie cognitive. Le problème essentiel se pauserait dans l'enseignement de «l'espace géographique» autant du point de vue déclaratif comme du point de vue procéssif. Nous resumons diverses perspectives de la conception de l'espace géographique et nous suggérons des processus pour rendre plus facile le développement et le procès de son enseignement et de son apprentissage.

Mots CLÉs: Espace. Didactique. Épistémologie. Connaissance procéssive.

AвSTRACT: Reflections on geographical space and its instruction. With this article we intend to summarize the main problems involved in the instruction of Geography bearing in mind both its characteristics as a science and the needs of pupils according to the principles of Cognoscitive Psichology.

The main issue to be considered is how to teach the notion of «geographical space», not only from a declarative but also from a procedural point of view. In order to do so, the concept of geographical space is analysed under different perspectives.

We suggest various activities so as to ease the teaching-learning process.

KeY words: Space, Instruction, Epistemology, Procedural Knowledge. 